\title{
"Pixels May Lose Kelp Canopy": The Photomosaic as Epistemic Figure for the Satellite Mapping and Modeling of Seaweeds
}

\author{
Melody Jue ${ }^{1}$ (D) $^{\text {a }}$ \\ ${ }^{1}$ English Department, University of California Santa Barbara \\ Keywords: media, oceanography, ocean, mosaic, seaweed, satellite, modeling, environmental media \\ https://doi.org/10.1525/001c.21261
}

\begin{abstract}
This article shows how the photo-mosaic characterizes epistemic practices in contemporary oceanography, particularly through the satellite survey and ecological modeling of marine macroalgae (seaweeds). Drawing on John Murray's 1912 formulation that oceanographic knowledge relies "upon a patiently put together mosaic representation of the discoveries" and Nancy Cartwright's description of theory in science as a patchwork, I examine the mosaic as both an organizational form for oceanographic knowledge-making and as an aesthetic that emerges in remote surveillance. Through a comparative analysis of the visual and computational media surrounding sargassum and giant kelp, I analyze how a photo-mosaic epistemics and aesthetics emerges through the squareness of pixels and mapping interfaces, and through the ways that discrete instances of sampling and observation are assembled into provisional pictures of understanding. Moreover, I argue that the visibility of sargassum and giant kelp to a satellite depends on what I call their "photo-availability," or the physical and metabolic qualities that make them sensible to satellite detection. In this way I consider seaweeds as active agents in the distributed media system of satellite imaging, rather than the passive objects of surveillance and monitoring, where epistemic mosaicking emerges as a strategy for knowledge and control.
\end{abstract}

John Murray, one of the naturalists aboard the famous HMS Challenger expedition (1872-76), once compared oceanographic research to a mosaic representation:

It has often been said that studying the depths of the sea is like hovering in a balloon high above an unknown land which is hidden by clouds, for it is a peculiarity of oceanic research that direct observations of the abyss are impracticable. Instead of the complete picture which vision gives, we have to rely upon a patiently put together mosaic representation of the discoveries made from time to time by sinking instruments and appliances into the deep, and bringing to the surface material for examination and study. (Murray 1912, 22)

In this passage, Murray references the difficulty of seeing and observing through the opacity of the ocean, likening seawater to a domain "hidden by clouds" and imagining the position of the oceanographer as a hovering, aerial

\footnotetext{
a Melody Jue is Associate Professor of English at the University of California, Santa Barbara, working across the fields of ocean humanities, science fiction, STS, and media theory. Drawing on the experience of becoming a scuba diver, her book Wild Blue Media: Thinking Through Seawater (Duke University Press, 2020) develops a theory of mediation specific to the ocean environment. She is the co-editor with Rafico Ruiz of Saturation (Duke Press, 2021) and coeditor with Zach Blas and Jennifer Rhee of Informatics of Domination (Duke Press, under contract). Professor Jue has also published articles in journals including Grey Room, Configurations, Women's Studies Quarterly, Resilience, and Animations: An Interdisciplinary Journal. Her new work explores the mediations of seaweeds in relation to photography, metabolism, and energy.
} 
viewer looking downward. The opacity of seawater presents obvious challenges to vision and clarity, hence the oceanographic turn to specialized instruments and nets that bring material (or data) to the surface. For Murray, each observation of the ocean contributes to a "mosaic representation" of oceanographic knowledge, assembled into an approximation of a constantly moving whole.

It is significant that Murray does not call the ocean itself a mosaic, but rather our knowledge of it - patched together to form a provisional understanding of the vast sea, a kind of craftwork requiring hand-assembly. As I have written elsewhere, composition by hand connects the traditional making of Ancient Greek tile mosaics with the kind of crafting that takes place on oceanographic cruises, which involve many last-minute power-tooled adjustments to instruments before their deployment in the ocean, prompting some scientists I observed to describe their work as "MacGyver-ing," after the popular 1990s TV show (Jue 2020). Such assemblages connect to the nature of mosaics as handcraft, where traditional methods of composition would have involved the careful mixing of cement and placement of tiles. ${ }^{1}$ Mosaicking emphasizes how oceanographic knowledge is not simply found, but made-not in the sense of being "made up," but rather as the effortful result of great investments of time and money to compose accurate sampling instruments and situate data into meaningful frameworks. ${ }^{2}$ Oceanographic knowledge does not preexist the choice to observe, measure, and construct through the interventions of the body.

Murray's epistemic attitude toward oceanographic knowledge-making as mosaic composition aligns with philosopher Nancy Cartwright's argument in The Dappled World: A Study of the Boundaries of Science (1999) that "claims to knowledge we can defend by our impressive scientific successes do not argue for a unified world of universal order, but rather for a dappled world of mottled objects" (Cartwright 1999, 10). For Cartwright, the "dappled world" is the provisional, patchwork composition of scientific laws, theories, and models that describe "the messy, mottled world that we live in" that is the "object of our scientific pursuits" (Cartwright 1999, 6). Science collectively responds to the precondition of the "messy, mottled world" through a patchwork of models, laws, and theories-useful in different situations, but never in every situation. To point out a simple homonym in Cartwright's description, the "mottle" of the world is that which comes before the scientific "model," which works "best in pockets, primarily inside walls," a special set of conditions "arranged just so" (Cartwright 1999, 2). While Cartwright's claim is more ambitious, describing epistemic practices of science in general rather than one

\footnotetext{
1 In the Oxford English Dictionary, definition 1c gives the example of a wood mosaic as a kind of traditional handcraft.

2 From my own experience (and seasickness) on an oceanographic cruise in December 2019, it was clear that you have to choose to go to sea, obtain significant funding, and physically move all the tonnage of equipment that you might possibly need for your experiments and sampling (Jue 2020).
} 
subdiscipline like oceanography, both she and Murray are drawn to the figure of the patchwork or mosaic as an aesthetic form that best describes the ad hoc-rather than totalizing - nature of scientific epistemologies.

I find the mosaic to be an apt metaphor for oceanographic epistemologies because of its role in ordering the mottle of the world into an organizing frame. Where the mottle is chaotic nature in the raw, the mosaic or patchwork is the body of knowledge that humans have intentionally developed to represent, model, and describe. Skeptical of any grand ultimate theory (GUT), Cartwright observes that the patchwork of laws that describe our physical world contains "pockets of great precision; large parcels of qualitative maxims resisting precise formulation; erratic overlaps; here and there, once and a while, corners that line up, but mostly ragged edges; and always the cover of law just loosely attached to the jumbled world of material things" (Cartwright 1999, 1). The mosaic of scientific knowledge, then, need not perfectly fit together or universally apply to every situation; in a pragmatic sense, it is the reservoir of laws, theories, models, and representations we draw up to actively assemble explanations of the material world.

However, what we expect the mosaic to account for depends on how we imagine its similarities to or differences from other artistic forms. Just as the common analogy "the brain is like a computer" very much depends on the kind of computer one has in mind (consider the vast differences between ENIAC and quantum computing), what one means by "mosaic" has implications for how we imagine epistemic practices in science. To what extent is a mosaic different from a collage (pasting paper cutouts on a surface) or bricolage (an artwork from "any materials that come to hand")? ${ }^{3}$ Tate Modern provisionally defines the mosaic as "a picture made up of small parts which are traditionally tiny tiles made out of terracotta, pieces of glass, ceramics or marble and usually inlayed into floors and walls," " while the Oxford English Dictionary connects the etymology of "mosaic" to the museum. "Mosaic" also finds use in the biological sciences, in terms like "tobacco mosaic virus" or "ecological mosaic." In aerial surveys, mosaics can be "a composite photograph or map, esp. one made up of a number of separate aerial photographs from overlapping areas" ("Mosaic" n.d.). Mosaic can also act as a transitive verb meaning "to form a larger composite image," as in "The digital data were combined, or mosaicked, to delineate counties or other areas crossing scene boundaries" ("Mosaicked"

\footnotetext{
3 “Bricolage," accessed January 2, 2021, https://www.tate.org.uk/art/art-terms/b/bricolage.

4 “Mosaic,” accessed January 2, 2021, https://www.tate.org.uk/art/art-terms/m/mosaic.

5 According to the Oxford English Dictionary, "mosaic" is of uncertain origin, although it may have derived from the Latin musaeum, or museum - "a place holy to the Muses" — on the principle that such shrines were decorated with mosaics, though curiously, "there is insufficient evidence to support this" and "museum may derive from an oriental language" ("Mosaic" n.d.). Nonetheless, the OED defines the art form of a mosaic as "The process of creating pictures or decorative patterns by cementing together small pieces of stone, glass, or other hard materials of various colours" or "of various materials analogous to traditional mosaic in method of production, [...] as paper mosaic, mirror mosaic, straw mosaic, wood mosaic." As an adjective in ecology, mosaic is often used to describe communities or associations; in genetics, it indicates a hybrid organism, or something causing mottling (like Tobacco Mosaic Virus [TMV]). In zoology, Johannes Müller's theory of “mosaic vision” describes vision in the compound eye of arthropods, where partial images combine to produce a complete one.
} 
n.d.). It is possible that overlapping pieces would imply a different kind of epistemic model: where the traditional mosaic made of small glass or ceramic tiles would involve abutted pieces, the aerial photomosaic would include overlapping edges. Thus, depending on the material specificity of the medium used, mosaicking practices present different relationships to the question of edges and boundaries. Neither Murray nor Cartwright address this question of materiality, imagining the mosaic and patchwork as abstract figures for knowledge-making.

For me, if mosaicking is to describe epistemic practices in twentieth- and twenty-first-century oceanography, then it needs to address visualization methods from technologies of remote observation and aerial surveillance. Where the mosaic offered a metaphorical touchstone to describe methods in nineteenth-century oceanography in Murray's description, I propose that the photomosaic is a more adequate epistemic metaphor for contemporary oceanography. Much oceanographic work today uses remote technologies of observation that include aerial photography, satellite monitoring, and drone surveys. The aerial positionality of these devices recalls Murray's analogical figure of "a balloon high above an unknown land," that hovering vantage point necessary for gathering mosaic elements for oceanography, but expands upon it. The images produced by remote satellite technologies visually evoke a mosaic aesthetics through the "squares" of individual photographs or digital pixels. However, the analogy I draw between pixels and tiles is only partial. The arrangement of pixels in a grid of rows and columns differs from the traditional mosaic of ancient Greece, where tiles could be angled in sweeping arcs to form the curved back of a fish, the curlicue wave pattern of a border, or ringlets of Gorgon hair. Another difference between traditional mosaics and remote oceanographic imagery is that satellite images of the ocean resolve only to specified scales, where certain areas of the ocean may equal only one pixel.

Satellite photomosaics also differ from the tile mosaics of antiquity through their different relationships to time, point of view, power, and militarization. Because the pixel is the smallest unit of resolution and the smallest unit of visibility, it has also been taken as the site of political struggle against surveillance technologies. Artist Hito Steyerl draws attention to the politics of the pixel in HOW NOT TO BE SEEN: A Fucking Didactic Educational .Mov File (2013), which parodies the pixel as marking the threshold of being seen and observed through remote surveillance. In this film, a robotic voiceover narrates, "To become invisible, one has to become smaller or equal to one pixel," as bodies in green suits dance around squares scaled to the minimum size of satellite detection. ${ }^{6}$ Photomosaic epistemologies in the ocean sciences,

6 Hito Steyerl, How Not To Be Seen: A Fucking Didactic.MOV File (2013), https://www.artforum.com/video/hito-steyerl-how-not-to-be-seen-afucking-didactic-educational-mov-file-2013-51651, accessed February 5, 2021. 
then, require careful consideration of which phenomena make themselves available to the thresholds of photographic detection, for whom this matters, and to what purpose.

Oceanography's use of remote observation technologies-satellites, aerial photographs, drones-also needs to be historicized within the context of militarization, surveillance, and reconnaissance. Paul Saint-Amour notes that photomosaics were first used during World War II for aerial reconnaissance, an early form of aerial surveillance that replaced slower on-the-ground mapping. Whereas the tile mosaic remains scaled to the human hand and depends on slow assembly, the photomosaic involves a patchwork of temporalities, indexed to the moment each photograph was taken. Far from self-evident views, photomosaics involved assembling and aligning many "individual stills, each of which had to be rectified and then harmonized with its neighbors. The resulting photomosaics were not so much taken as produced, often by workers trained in the highly technical business of compensating for tilt, blur, vibration, and paper shrinkage and expansion" (Saint-Amour 2011, 243). For Saint-Amour, the labor involved in calibrating photos to each other suggests that "seeing is an event rather than a condition; that we always see from some when" (Saint-Amour 2011, 246). Saint-Amour's connection between the photomosaic and aerial reconnaissance draws our attention to the specter of warfare as a precondition for aerial vantage points and ways of seeing. Much has been written about the coincidence of the aerial view with the bomb's-eye view (Arendt [1958] 1998; Virilio [1977] 2006; Kaplan 2018), a position that tends to see the world as "target" (Chow 2006).

In contrast to the aerial photography of the early and mid-twentieth century with airplanes, late twentieth- and twenty-first-century oceanography relies on satellite observation, intensifying connections to militarization and surveillance. Lisa Parks notes that remote-sensing satellites were initially developed as "technologies of espionage" by the United States during the early 1960s as part of the top-secret Corona program (Parks 2005, 78). It was not until 1972 (after the end of the Corona program) that "NASA launched the first public remote-sensing satellite, Landsat, which took unclassified pictures of the earth for use in natural resource management" (Parks 2005, 78). Landsat images have since been mosaicked into the composite of Google Earth, whose "seams" are apparent from different scales of zoom, resulting in "a mottled mash of icons, indexes, and symbols of the marine and maritime world" (Helmreich 2009, 1211). Satellite images do not capture images of the earth so much as process and filter a set of particular sensations. In Program Earth, Jennifer Gabrys writes against an "automatic understanding of sensors [like satellites] as merely detecting preformed environmental data as though there is a world of substantialist phenomena to be processed by a cognizing device" (Gabrys 2016, 10). Like Gabrys, Parks cautions against the notion of one-toone correspondence between satellite images and reality: "the satellite image must be grounded - that is, read, decoded, and contextualized-in order to 
signify anything other than its orbital perspective, to even remotely make sense" (Parks 2005, 113). Satellite photography of the earth and oceans is, to use Parks's term, a televisual experience that requires a great deal of processing before it becomes useful.

I am interested in the photomosaic aesthetic and epistemology that emerges from surveying marine macroalgae (seaweeds) because of the entanglement between their physiology and what I call their "photo-availability" to satellite detection. Macroalgae, or large algae, are wide-ranging organisms and undersea "forests" that have been the subjects of a number of satellite surveys and ecological modeling. Macroalgae is a broad umbrella term for three phyla of seaweeds that include red seaweed (Rhodophyta), green seaweed (Chlorophyta), and the more distantly related brown kelp (Phaetophyta). Although macroalgae share some similarities with plants, they are far older on an evolutionary timescale, and absorb nutrients throughout their bodies instead of having a distinct vascular system. ${ }^{7}$ Macroalgae provide habitats for fish and many other marine organisms (for example, the giant kelp and sargassum discussed in this article), and play a key role in storing carbon and producing oxygen. Economically, they are a valuable source of gel-like extracts (carrageenan, alginate, agar) that permeate consumer culture, appearing in cosmetics, ice creams, toothpastes, and a variety of industrial products that need a gluey substance to hold together (Mouritsen 2013). Yet as I explain shortly, seaweeds like sargassum can disrupt livelihoods when they overproliferate and inundate beaches, driving the development of new forms of satellite detection and modeling, while other seaweeds like giant kelp form entire ecosystems that are essential to marine health.

I choose marine macroalgae not only as the subjects of satellite photographic survey but also as participants in a photographic media ecology due to their metabolism - they photosynthesize, producing energy from sunlight. I use the concept photo-available to indicate how macroalgae are detectible to satellites by virtue of their physiology (including their buoyancy, possession of chlorophyll a, and nearness to the ocean surface) and environmental factors (such as reflectance of seawater, cloud cover, tidal action), long before they appear as tinted pixels on a digital scan. Photo-availability names a condition by which photosensitive organisms actively participate in their own image-making. Here I expand on Henry Fox Talbot's concept of the "pencil of nature" to describe the way nature inscribes itself in calotype photography (Talbot 1844). Rather than looking only at the moment of inscription on a photosensitive surface, as Talbot did, I consider the way that the entire life cycle, physiology, and metabolism of seaweeds sets them up to become photo-available to satellite

\footnotetext{
7 Brown algae are also referred to as kelp and are genetically more similar to diatoms than to the red and green phyla. Macroalgae have three major structures (holdfast, stipe, blades) that roughly correspond to roots, stem, and leaves in plants-with the major difference being that plants have a vascular system for transporting nutrients, and seaweeds are absorptive (rootlike) everywhere. Macroalgae are also far older than plants, although surfgrass (which can be found in the ocean) is a plant that migrated back to the ocean and does have a vascular system.
} 
detection. This ecological and durational understanding of photography offers a different approach than theories of photography that obsess over "what has occurred only once" (Perloff [1995] 2018) by emphasizing the material preconditions necessary for macroalgae to be detectable to the infrared scans of orbital satellites.

I focus my discussion of the satellite surveyal and mosaicking of two distinct genera of macroalgae: giant kelp (Macrocystis pyrifera) and sargassum (Sargassum natans and Sargassum fluitans). Sargassum is a free-floating seaweed that not only gives name to the Sargasso Sea but also commonly drifts in patches in the Caribbean Sea and the Atlantic Ocean. Giant kelp, meanwhile, is a keystone species in cold Pacific waters, known for the large and fast-growing canopies that it sends up to float along the surface of waters like those around Santa Barbara, California, where I live. These two species enable me to compare not only the particularities of their habitats-Pacific Ocean and Caribbean Sea, respectively_-but also the cultural motivations for modeling their distribution. Whereas modeling sargassum responds to a crisis of overproliferation and the need to know when fresh mats will inundate shorelines, modeling giant kelp is part of decades-long ecological research that tracks change over time. ${ }^{8}$ I offer this Caribbean/Pacific contrast within the context of this special issue on "Modeling the Pacific" to show how a photomosaic aesthetic and epistemology exists both within and beyond the Pacific Ocean, emerging from the aerial surveillance of marine macroalgae in a global context.

\section{Blazing like a Bonfire}

What does seaweed look like from outer space? To answer this question, we should know something about what seaweed looks like at the sea level and the qualities that make it photo-available to satellite cameras. In the Atlantic, sargassum is a free-floating brown seaweed that floats on top of the water in large mats, a tangle of golden habitat. It famously gives its name to the Sargasso Sea, in the northern Caribbean. Rachel Carson once called the Sargasso Sea "a place forgotten by the winds, undisturbed by the flow of waters that girdle it," populated by seaweeds that were once torn away from rocks and carried by the currents: "With the weeds go, as involuntary passengers, many small fish, crabs, and shrimps, and innumerable larvae of assorted species of marine creatures" (Carson 1951, 44). Of the two varieties present in the Atlantic, $S$. natans is generally thinner, while $S$. fluitans has larger air bladders and more densely packed blades. Although often mistaken for plants because of their shape and the fact that they photosynthesize, seaweeds are actually macroalgae-an organism far older, in evolutionary terms, than plants. 
Yet it is this ancient capacity to photosynthesize that makes seaweeds like sargassum and giant kelp available to the visual detection systems of satellites. The pigment chlorophyll a reflects infrared light more strongly than the surrounding seawater. This enables an important degree of contrast, not visible in the true color spectrum for humans. Put another way, chlorophyll makes seaweeds photographically detectable to satellites through the optical medium of the atmosphere. One article on the beach accumulation of sargassum offered the following metaphor: "To satellites that detect infrared, sargassum blazes like a bonfire" - a figuration that seems to echo the golden color of the sargassum itself (Atlantic 2019). The photo-availability of seaweeds to satellites relates, then, precisely to their own metabolic ability to photosynthesize light.

However, it would be a mistake to assume that this "bonfire" of sargassum is accessible, easy to see, and self-apparent, even to a satellite. Chuamin $\mathrm{Hu}$, a researcher at the University of South Florida, writes that accurate and timely detection of sargassum mats using algorithms has been "difficult or even impossible due to lack of spatial resolution, coverage, revisit frequency" ( $\mathrm{Hu}$ 2019, 2118). Indeed, the frequency of "seeing" the bonfire of seaweed depends on the satellite system with which one is working: MODIS or Landsat. MODIS (Moderate Resolution Imaging Spectroradiometer) has a daily "revisit cycle" but can produce only images with a resolution in which one square kilometer is represented by one pixel. ${ }^{9}$ By contrast, Landsat produces higher resolution images, where one pixel is the size of a thirty-square-meter area. Landsat orbits Earth only every sixteen days, a longer interval that reduces the representativeness of its images.

The squareness of pixels and, at a larger scale, overlapping satellite photographs suggests a photomosaic aesthetic and epistemology in sargassum monitoring. However, a photomosaic epistemology should not take for granted the preexistence of each mosaic tile but should attend to the ways that technologies process, produce, and frame them. Just as Saint-Amour emphasizes the heterochronicity of the aerial photomosaic, Parks cautions that "Our understanding of the temporality of the satellite image should be derived through the process of its selection, display, and circulation rather than formed at the instant of its acquisition" (Parks 2005, 91). Indeed, satellite images of seaweeds undergo algorithmic processing after the event of image capture. The infrared "signature" of floating algae can be mistaken for other types of algae farther down in the water column, including sediment plumes, clouds, or other atmospheric phenomena (Hu 2019, 2119). To address this, Hu developed an algorithm called the Floating Algae Index (FAI) to improve on the Normalized Difference Vegetation Index (NDVI), which is generally better at telling the difference between algae and water-or, more specifically, "truth is defined as the difference between the 'Algae' pixel and the nearby 'Water' pixel” (Hu 2019, 
2120). This emphasis on the pixel marks the author's focus on the provisional nature of the model, in correspondence with the material reality of the ocean. What "blazes like a bonfire" to a satellite is one highly processed pixel, whose character depends on satellite resolution, revisit frequency, and the specific algorithm used to process the data.

\section{Pixels May Lose Kelp Canopy}

Like sargassum, satellite imagery of giant kelp ( $M$. pyrifera) shows how mosaicking is not only about the assembly of tile-like pixels and square scans into a composition but also about the importance of hand-assembly in the gleaning of knowledge and the generation of models. While satellite images seem to offer a form of objectivity from above, there is a high degree of handediting that goes into image processing. Take, for example, the project Floating Forests, which enlists citizen scientists to help graphically circle patches of giant kelp in a series of satellite images. In their "Why do we need your help?" section, Floating Forests project organizers explain that they had once hoped to develop software to reliably read the images and detect kelp:
There's just one problem: Kelp is tricky. Landsat was not designed to be able to see kelp. Kelp's reflectance signature (the color of light that it reflects) is just at the edge of the camera's detection abilities. Because of this, kelp and something as simple as the glint of sun off of a wave look the same to a computer. But to a person, the shapes and patterns of kelp forests are fairly obvious. That's where you come in. By tracing patches of kelp, you can do a far more accurate job than a computer, helping to process this mountain of data! $!^{10}$

This project statement preserves a difference between how computers and humans sense difference itself. Because machine learning has yet to develop adequate methods for identifying seaweed in a satellite scan, the Floating Forests project enlists citizen scientists as pattern detectors, able quickly to look at a satellite image and tell where kelp exists by recognizing its "shapes and patterns"-its signature patchiness. The interface invites participants to use their mouse cursor to trace neon-green lines around relevant patches (figure 1), a color perhaps selected for its affinity to photosynthesizing algae. In this way, Floating Forests shows how turning a "mountain of data" into a mosaic of knowledge about the global distribution of giant kelp is dependent on the slow, monotonous labor of many hands digitally tracing kelp patches.

While Floating Forests would seem to suggest a clean distinction between human and satellite vision, not every satellite sees in the same way. As researchers at UC Santa Barbara note, updates to Landsat satellites over the 


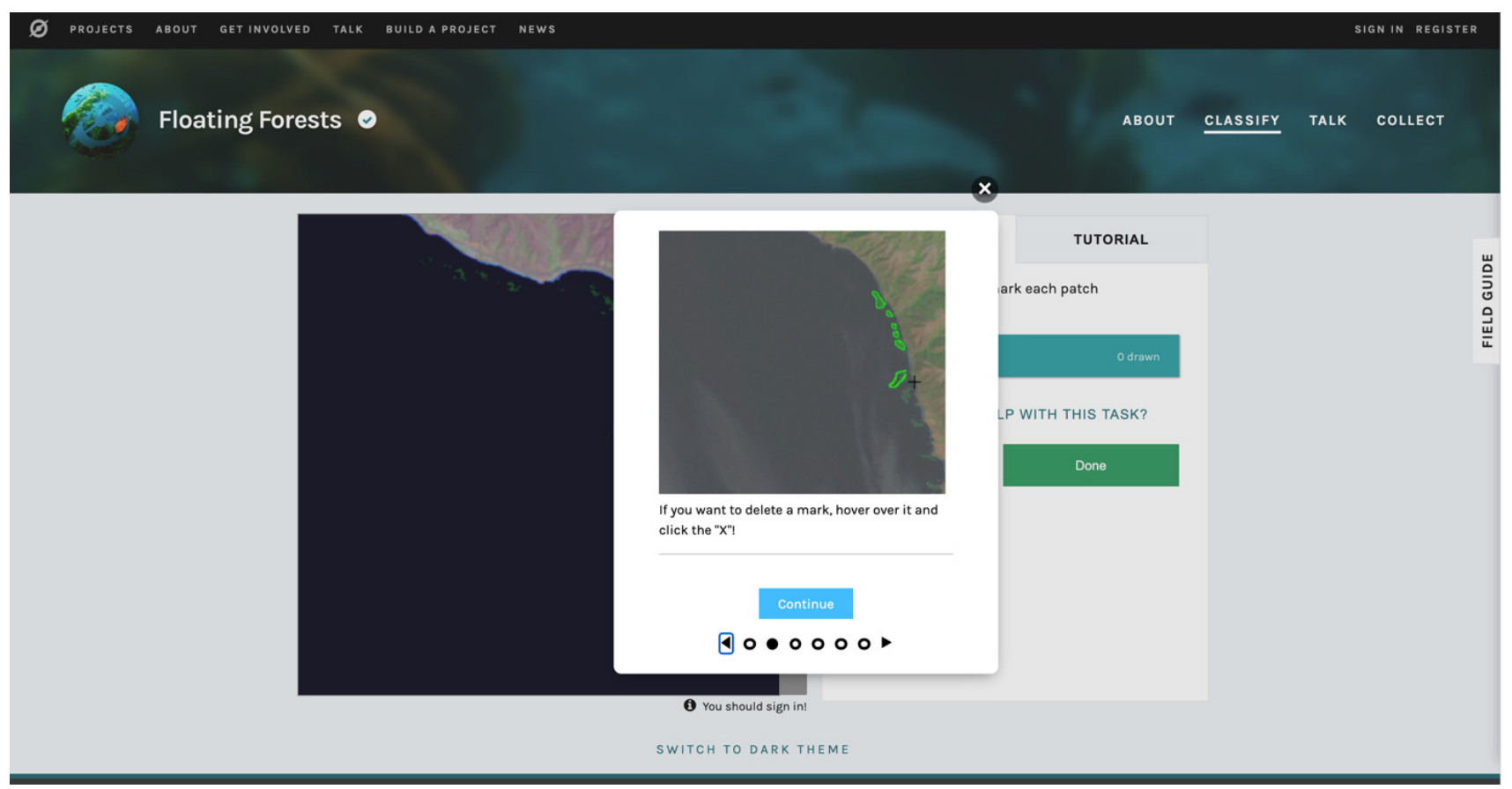

Figure 1: Floating Forests instructional direction, showing how to highlight patches of kelp forest. Screenshot from https://www.zooniverse.org/projects/zooniverse/floating-forests/classify.

years have involved changes in spectral response functions and signal-to-noise ratio (Bell, et al. 2019). Sensor degradation, instrument noise, and response function biases also affect satellite vision. One mechanical failure-the Landsat 7 ETM+ scanning line-resulted in a zigzag pattern of black lines on all satellite images of the Santa Barbara LTR (Long Term Ecological Research) station, prompting researchers to develop mathematical estimations to fill in the gaps and categorize each pixel as seawater, cloud, land, or kelp. While the final product looks like a single photograph, it is actually a composite that has been smoothed over and edited by researchers to fill in absences resulting from this glitch.

The promise of satellite photography in mapping seaweed is thus similar to that of Crittercam, a remote camera attached to creatures like whales, seals, and turtles, that Donna Haraway calls a kind of "compound eye." For Haraway, the "compound" suggests both the enclosure of a prison and the multiplicity of an insect eye-evocative of a mosaic aesthetic - by enabling scientists to see together with a seal, but askance through the sideways position of the camera. Crittercam attempts to eliminate human presence and allow "us entry into otherwise virtually inaccessible habitats" (Haraway 2007, 141). Karen Barad makes a different point about compound eyes in her discussion of the brittlestar, which has a skeleton with crystals that effectively functions as a visual system. "Brittlestars do not have eyes. They are eyes. That is, it is not merely the case that its visual system is embodied. Its very being is a visualizing apparatus. The brittlestar is a living, breathing, metamorphosing optical system" (Barad 2014, 227). In a description that is evocative of a mosaic, Barad 
cites a Bell Labs scientist who "likens the brittlestar to a digital camera that builds up a picture pixel by pixel” (Barad 2014, 224). As a compound eye, the brittlestar does not represent a mosaic of knowledge to itself; it would be more accurate, within Barad's view, to say that the brittlestar is the mosaic at the level of embodiment.

In the case of giant kelp, the body matters in the way that it makes itself available to the detection of a satellite scan. However, the photo-availability of giant kelp forests to satellites is different from sargassum due to several key morphological factors. Where sargassum floats in mats in the open ocean up to three meters in depth, only the canopy of giant kelp is available for satellite detection. ${ }^{11}$ As a towering forest of habitat in colder waters around the world, sometimes growing over one hundred feet in length, giant kelp produces a swirl of blades held aloft by ovular, grape-like bladders that enable a long, trailing frond to float at the ocean's surface. This canopy is the only part of the giant kelp that is photo-available to satellites, accessible precisely because of its buoyancy and the morphological feature of air bladders that help the canopy float at the surface of the ocean.

Because giant kelp lives in relatively shallow waters near the coast instead of the open ocean, tides and currents can affect the length of canopy reaching the surface. As Bell notes, "a higher tide level will pull a portion of the fronts under water as the holdfast is static on the rocky reef below and will decrease the amount of frond that lies horizontal on the surface" (Bell, et al. 2019, 4). The tide was also a factor in the photomosaics of aerial reconnaissance during World War II: "The shoreline had to be photographed at low tide for consistency's sake and to capture as much dry land as possible" (Saint-Amour 2011, 260). In the case of satellite imaging of giant kelp, it is not possible for researchers to correct for differences in tide at every scale of resolution: "While this tidal adjustment method works well at the patch scale, entire Landsat pixels may lose kelp canopy during high tide events around the edge of the patch" (Bell, et al. 2019, 6). This phrasing preserves the distinction between the model and the corresponding material reality of the oceanic seaweed. While the authors could have written that a square of seawater loses kelp canopy during tides, they chose instead to emphasize the pixel-the unit of photomosaic vision-losing kelp canopy. Here, the pixel itself is the meaningful unit of composition for the mosaic oceanographic knowledge.

Mosaicking can also involve temporal sequences of organized data. The Santa Barbara Channel is home to several long-term ecological research stations that have more than forty years of sustained and publicly available observations. Aerial surveys of giant kelp patches are part of maintaining this data record, which can be used to study events that influence ecosystems across a longer

11 “Sargassum: A Complex 'Island' Community at Sea," accessed July 14, 2020, https://oceanexplorer.noaa.gov/explorations/03edge/ background/sargassum/sargassum.html. 
duration of time. In this way, surveying and modeling the growth of giant kelp forests in Southern California contributes to a broad understanding of how the kelp forest has changed over time, as well as potential applications for marine aquaculture as an energy source. For example, ARPA-E currently funds the MARINER project, led by UC Irvine, which aims to produce a modeling tool for assessing optimal sites for macroalgae cultivation and maximal yield. ${ }^{12}$ In the Pacific Northwest and Northern California, aerial surveys are needed to trace the quickly disappearing forests of bull kelp (Nereocystis), a key part of coastal ecosystems. ${ }^{13}$ However, if disappearance is a concern with bull kelp and giant kelp, proliferation is the more salient problem with sargassum. As I explain next, researchers have very different motivations for surveying and modeling growth cycles of Pacific kelp forests than they do for modeling sargassum in the Caribbean.

\section{Forecasting Alien Invasions}

In the Caribbean, the "bonfire" metaphor not only describes how seaweeds appear to a satellite but also unintentionally signals a wish fulfillment: that piles of sargassum could be burned away. Since 2010 something has been causing massive summer blooms to pile up on beaches all around the Caribbean, affecting tourism, fishing, and the lives of animals, like nesting sea turtles, that depend on beach access. More than an unsightly tangle, decomposing sargassum gives off hydrogen sulfide gas, which has the smell of rotten eggs. According to one report, "the sight and smell left beaches highly unattractive, and swimming was impossible. On land, the gas rapidly destroyed nearby electric units, such as TVs; eroded metals and even affected human health, with people living near inundated areas complaining of headaches, nausea and skin irritation" (Guardian 2018). A Belize hotel owner described the mass of seaweed as "something out of a science fiction movie" (Guardian 2018). Through its visual spectacle of the coastal takeover, sargassum channels the metaphor of the "alien ocean," a figure that Stefan Helmreich identifies in some cultural constructions of the ocean (Helmreich 2009).

The characterization of sargassum as an alien invader appears not only in discursive constructions, like interviews, but also in scientific literature. The journal Science echoed the imagery of invasion in an article entitled "Seaweed, seaweed everywhere," a short one-page companion to a longer article on "the great Atlantic Sargassum Belt," a recurrent pathway extending from West Africa to the Gulf of Mexico (Wang et al. 2019). "Seaweed, seaweed everywhere" references a famous line from Samuel Taylor Coleridge's classic poem “The Rime of the Ancient Mariner” ([1798] 2013): “water, water

12 “Macroalgae Cultivation Modeling System," accessed July 14, 2020, https://arpa-e.energy.gov/?q=slick-sheet-project/macroalgae-cultivationmodeling-system.

13 According to the California Department of Fish and Wildlife, more than 93 percent of the state's bull kelp forests have disappeared in the last five years, due to a number of environmental factors including a marine heat wave in 2014 and the onset of a starfish wasting disease in 2013 that left the kelp vulnerable to predation by sea urchins. 
everywhere / nor any drop to drink." The invocation is apt, for it not only keeps the same meter of seven syllables but also indicates an abundance of tainted or unusable resources. Just as the ancient mariner finds himself thirsty but adrift at sea in the original poem, Caribbean beaches are being inundated with an excess of unusable sargassum (although some efforts have been made to appropriate it for compost). "Seaweed, seaweed everywhere" acts as not only a literal description, then, but also an emotional response of despair to conditions of being surrounded by an unusable resource. This frustration is recapitulated in the last sentence of the same article in Science, which concludes by calling sargassum a "severe and perpetual nuisance" (Wang et al. 2019, 86) - a value judgment that seems to break the supposed objectivity (as disinterested observation) of a scientific publication.

Such despair at the arrival of massive seaweed mats-from both centers of tourism and local towns-is driving new efforts to model and forecast sargassum in the Caribbean. It is important to note that such modeling efforts do not arise in a cultural vacuum but are very much situated (Haraway 1988), arising from specific community needs-and these needs drive funding structures for modeling research. The Atlantic reported Antigua's environment minister, Molwyn Joseph, forecasting the following about sargassum blooms: "We have made the assumption that this is going to be an annual thing, and the same way we prepare for hurricanes we have to prepare for Sargassum" (Atlantic 2019). ${ }^{14}$ Where hurricanes arrive by air, sargassum mats arrive by water, destructive of lifeways and economies on different temporal scales. Furthermore, both seaweed blooms and hurricanes are mapped and tracked through the technology of satellite monitoring, which takes advantage of the optical properties of chlorophyll a and clouds to develop useful forecasts for preparation and mitigation.

If seaweed blooms are at least partially anthropogenic in origin-one recent article suspects Amazon deforestation and fertilizer runoff ( $\mathrm{Hu} 2019$ ) - then anthropogenic climate change is not just about the intensification of weather but actually about new forms of biological weather. ${ }^{15}$ Just as satellites track the landfall of hurricanes, satellites are also used to forecast when massive sargassum mats will come ashore. These forecast visualizations exhibit a mosaic aesthetic through the interpretation of individual image pixels as kelp/not kelp and in the visual aesthetics of their interfaces. For example, a sargassum

\footnotetext{
14 “Great Atlantic Sargassum Belt Is Here to Stay,” accessed July 14, 2020, https://www.theatlantic.com/science/archive/2019/07/great-atlanticsargassum-belt-here-stay/593290/.

15 Chuamin Hu's 2019 article in Science entitled “The Great Atlantic Sargassum Belt” gained international attention for tracing the yearly geographic flow of sargassum from West Africa to the Caribbean, floating the hypothesis that deforestation and nutrient runoff in the Amazon may be contributing to the now yearly inundations of sargassum in the Caribbean. However, in an interview in the Atlantic, Hu emphasizes that this conclusion is largely speculative due to lack of data. For example, his team could find data on the nutrients in the Amazon only for two years: 2010 and 2018. "I don't think there's enough data," Hu said. "It takes a huge amount of money to go there and take measurements." While the full picture of what is causing sargassum blooms has yet to be fully developed, it is likely that anthropogenic agency has some role to play. See "Great Atlantic Sargassum Belt Is Here to Stay," accessed July 14, 2020, https://www.theatlantic.com/science/archive/2019/07/greatatlantic-sargassum-belt-here-stay/593290/.
} 


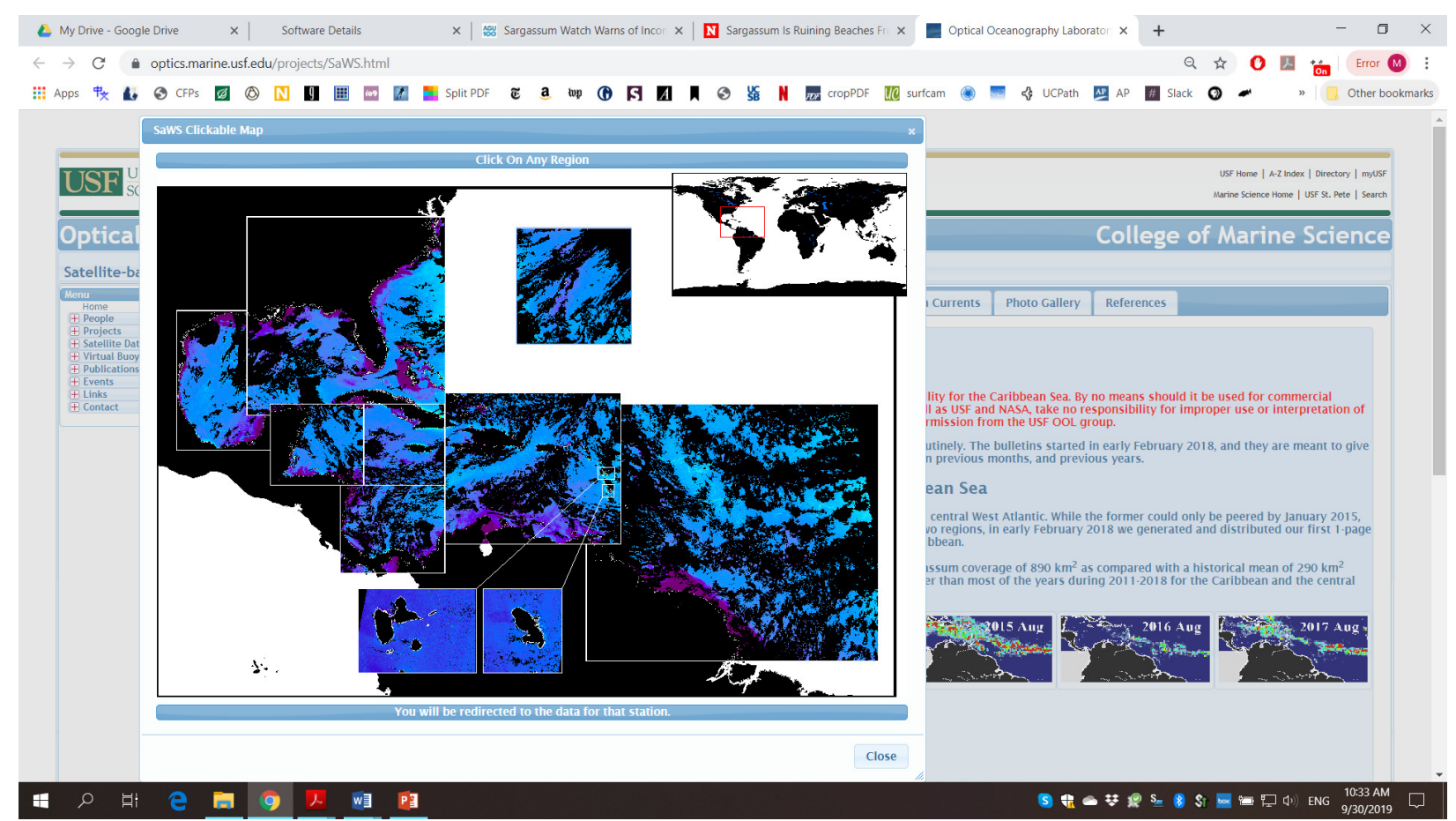

Figure 2: SaWS (a seaweed early warning system) interface. Screenshot from https://optics.marine.usf.edu/projects/ saws test.html.

modeling system from the University of South Florida's Optical Oceanography Laboratory called SaWS, or Satellite-Based Sargassum Watch System (figure 2), offers a clickable map of the Caribbean, where you can look at specific regions in detail. Through its overlapping square insets of specific regions, SaWS visually demonstrates the aesthetic of a mosaic or a collage, each square a portal into a closer zoomed-in view. Clicking on one region allows you to see recent scans of it from several different satellites, indicated by different tabs (e.g., MODIST, MODISA, VIIRS). The data from each satellite scan is then rendered into a false-color image, made with a different algorithm and for a different purpose. For example, the AFAI (Alternative Floating Algae Index) image was composed with an algorithm to detect algae at the scale of one square kilometer. ${ }^{16}$

Sargassum prediction - in parallel to weather prediction-matters so that local agencies know when to plan cleanup efforts, which involve coordinating large workforces and equipment. Investment has gone into floating barriers, rakes, and larger machines or boats capable of sorting sargassum from seawater. An article from July 2019 estimated that sargassum cleanup had cost Caribbean nations, collectively, US\$120 million, a cost that can only be expected to increase (South Florida Caribbean News 2019). Sargassum cleanup is big business, in order to keep the tourism industry figuratively afloat through the 


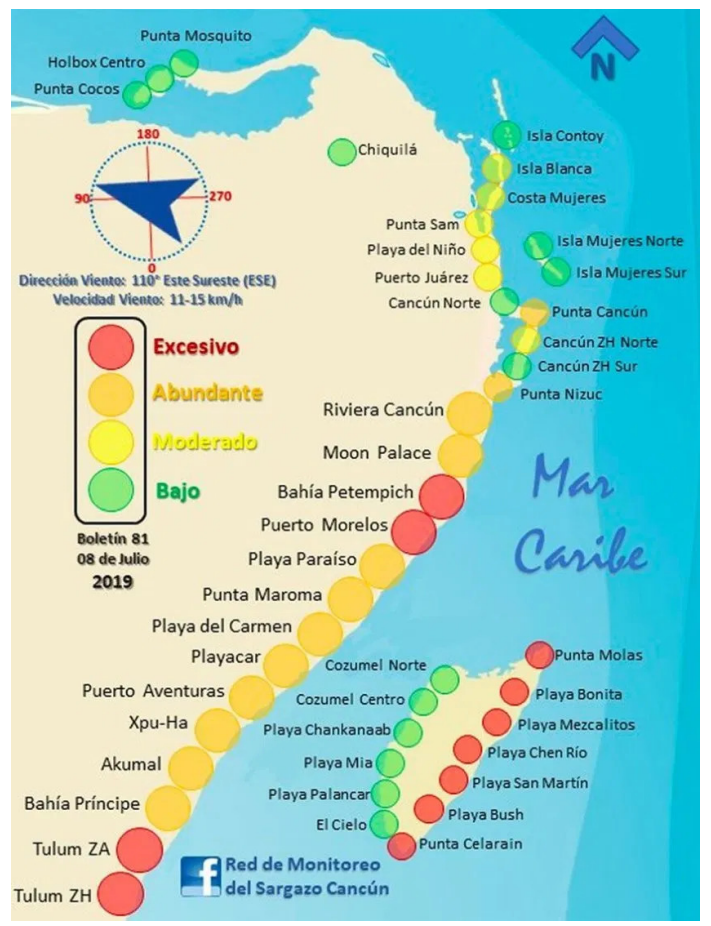

Figure 3: Map of Caribbean beaches with sargassum (red) from Sargassum Monitoring Network, cited in Mexican News Daily, July 3, 2019 https://mexiconewsdaily.com/news/huge-sargassum-arrival-blankets-beaches/.

restoration of beaches. It is with tourism in mind that sargassum maps of the Mayan Riviera have been produced each month, showing which cities (and tourist resorts) are less impacted by sargassum based on a color-coding scheme (figure 3), with green being clean and red marking sargassum inundation. The Twitter accounts Sargassum Monitoring and Sargassum Watch regularly report which beaches are free of sargassum (figures $4 \mathrm{a}$ and $4 \mathrm{~b}$ ). One travel blogger wrote, "It may seem self-indulgent to hold the 'I came to this pristine beach and all I found was this mound of smelly seaweed instead' postcard, but it's a reality and a problem that keeps coming back," begging the question: Who is sargassum monitoring for? Wealthy tourists, lucrative beach resorts, or locals trying to make their living? ${ }^{17}$

\section{Antiphotogenic Media}

Although sargassum interrupts all kinds of multispecies lifeways, it is precisely the image of the perfect Caribbean beach-and the tourism it enables-that belies the images produced by sargassum modeling and forecasting. The pristine beach exists in advertising images, which frame the Caribbean as a homogenous playground for wealthy tourists, devoid of local people. Such photographs commonly feature empty hammocks, blank stretches of sand, and possibly a few white tourists - rendering the Caribbean into a composite image of these vacation features. Krista Thompson's An Eye for the Tropics (2006)

17 "Sargassum Seaweed in the Caribbean: Will It Ruin My Beach Vacation?,” accessed July 14, 2020, http://www.weleavetoday.com/sargassumseaweed-caribbean/. 


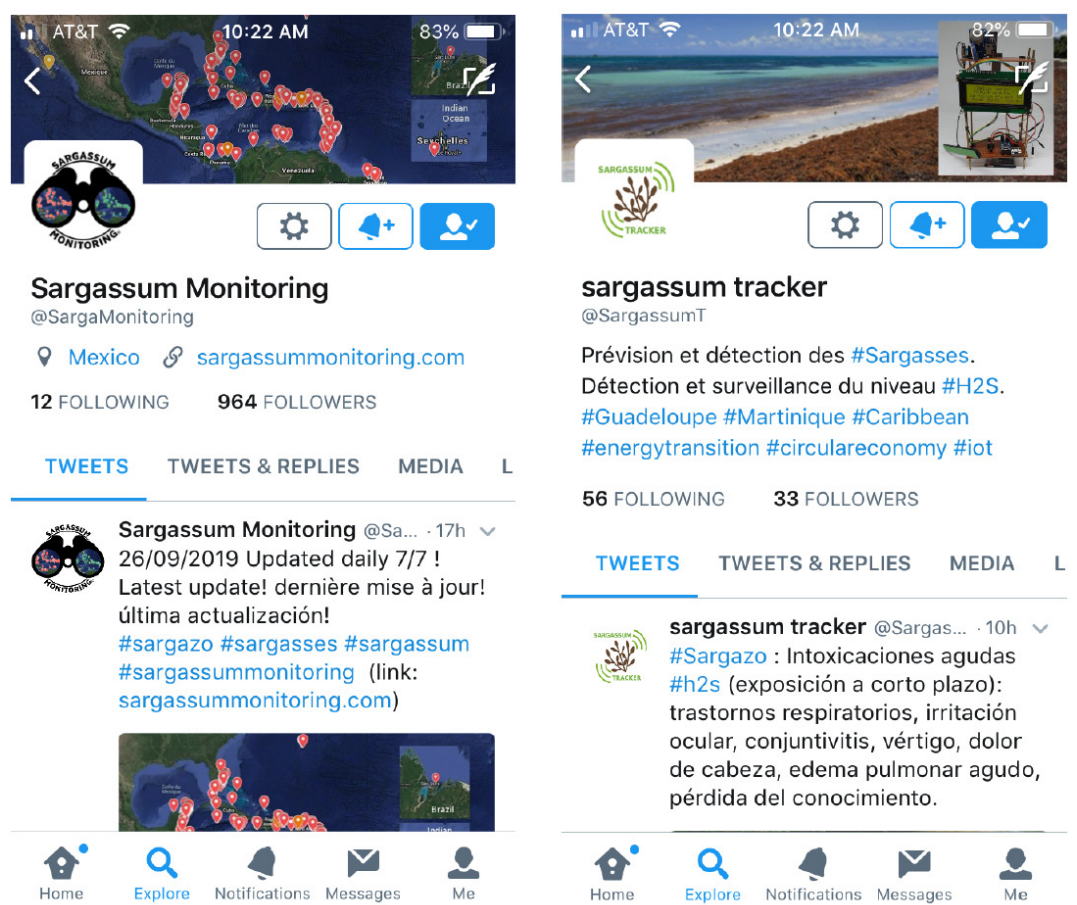

Figures $4 \mathrm{a}$ and 4b: Examples of sargassum tracking accounts on Twitter. Screenshots of @SargaMonitoring and @SargassumT.

traces this production of the empty "tropical” Caribbean to British colonists in the 1880s, showing how the circulation of images of pristine beaches and blue waters projected an image to the outside world that, in turn, altered everyday life on the islands. They not only attracted hordes of tourists but also restricted where local islanders could exist. As Beatriz Llenin Figueroa writes, "countless beaches in the Caribbean have been privatized, their access restricted to hotel patrons, and their uses submerged in deeply problematic sexual, racial, and class politics" (Figueroa 2012, 188).

Sargassum's effect on the image of the pristine beach gives it a complex relationship to photography. Earlier, I described how sargassum and giant kelp are photo-available to satellite image capture because of the pigment chlorophyll a. The reflective properties of chlorophyll a make these seaweeds possible to detect from the vantage point of outer space-a position so often equated with the God's-eye view (Haraway 1988). Here, the process of photography is not restricted to the inside of a camera but rather depends upon the optical affordances of seaweed, water, clouds, atmosphere, satellite, and algorithms for the final production of an image. This is a distributed model of photography, its mechanics and media strewn across many component elements, including seaweeds themselves. The photo-availability of seaweeds involves morphological properties that include air-filled bladders, which help the seaweed float and thus remain visible near the surface of the ocean (rather than lower in the water column). 
Yet unlike giant kelp_-and because of the nature and scale of sargassum mats in the Caribbean - it is possible to say that sargassum is also an antiphotogenic medium to the extent that it disrupts the image of the pristine Caribbean beach, piling high over beach sands with a strong, sulfurous odor. It prevents the perfect Instagram shot, even as it also interrupts the lives of sea turtles, local fishermen, and other lifeways. As a tangle of seaweed nested with other animal species, sargassum makes its own multispecies claim on the territory of the beach, one that is incredibly difficult to remove given the volume of beached seaweed. Sargassum interrupts the settler-colonial fantasy of the empty beach without people, ready for tourist occupation. Thus, even as sargassum plays into a distributed photographic ecology that includes its own chlorophyll a pigment and the infrared sensors of satellites, it is also an antiphotogenic medium to the extent that it disrupts the practice of photographing pristine Caribbean beaches that play into an idealized fantasy of emptiness.

To be precise, then, the antiphotogenic quality of beached sargassum necessitates photomosaic epistemologies as a strategy for tracking and mitigating its overproliferation. Or, put more simply: the sargassum is unsightly, hence the need to mobilize and draw on the expensive apparatus of satellite monitoring and prediction. As Parks reminds us, "The satellite is arguably one of the most elaborated forms of capitalism since it embodies immense financial investments, years of strategic planning, and pools of scientific labor" (Parks 2005, 7). The photomosaic work of satellite images and predictive modeling in the Caribbean-all the technical work that goes into forecasting the movements of seaweed pixels-is aimed to predict, control, and address this proliferation of sargassum, an interruption to the smooth flow of capitalism. In this way, photomosaicking knowledge of sargassum is not an impartial scientific practice but a financially motivated endeavor aimed at mitigating the seaweed's impact on resort profits. By contrast, the photomosaic work of mapping and modeling giant kelp in Southern California responds to very different economic and cultural circumstances. The waters of Southern California-in close proximity to several research universities-are some of the most studied in the world, and provide the opportunity for establishing a long-term record of seasonal giant kelp growth to monitor its changes under increasing anthropogenic pressures, including climate change. With giant kelp, the motivation for photomosaicking knowledge is not about getting rid of an antiphotogenic nuisance, so much as it is about keeping track of a valuable resource, with an eye to applications in aquaculture and energy, especially in the case of ARPA-E's MARINER project.

\section{Conclusion}

I have contrasted Caribbean and Pacific contexts for modeling seaweeds within this special issue on "Modeling the Pacific" to show how a photomosaic epistemology and aesthetics shape oceanographic uses of satellite vision. This emerges most strongly through the scale of the pixel, the smallest square unit of identification, whose resolution depends on which satellite system-Landsat 
or MODIS-detects the seaweeds. Yet the story of seaweed detection also involves the agency of seaweeds themselves, which become available to photographic capture. Photo-availability names the metabolic and morphological features of seaweeds that participate in bringing them to the surface of the ocean, the precondition for satellite detection of floating seaweed that "burns like a bonfire." The pixel of seaweed is not a self-evident feature of a satellite scan - so similar to a mosaic in its gridded form-but something that is contingent on existing technologies, algorithms, and human identification.

The photomosaic names not only an aesthetic in oceanography but also an epistemological relationship to satellites for remote visual surveillance. Recall how, as mentioned at the beginning of this article, John Murray of the Challenger expedition wrote that "we have to rely upon a patiently put together mosaic representation of the discoveries made from time to time by sinking instruments and appliances into the deep, and bringing to the surface material for examination and study" (Murray 1912, 22). The discrete act of sampling itself is what oceanography shares in common with mosaic-making, where each act of sampling or observation is a piece that can be assembled into a "mosaic representation" of knowledge. The long-term record of giant kelp growth and senescence contributes to this kind of temporal mosaic, patiently assembled for more than forty years. ${ }^{18}$ Floating Forests invited citizen science contributions from those willing to hand-trace pixels of kelp in their efforts to assemble knowledge of how the forests change over time. Here, mosaicking describes the intentional assembly of scientific knowledge piece by piece, often collaboratively via the work of many hands.

Yet as I have shown in the case of sargassum, mosaicking can also be an extension of efforts to predict and control that which undermines colonialist extensions of capitalism, as when huge swaths of sargassum inundate luxury resorts in the Caribbean. These unsightly and sulfurous piles disrupt the smooth flow of tourists and profit, turning what were beautiful beaches into unwanted sites of decomposition. The photomosaicking epistemics of satellite tracking and surveillance-piecing together snapshots over time-is in a sense a counterstrategy against the miasmatic arrival of sargassum. Mosaicking strategies exist not as the pure aspiration of science but, instead, always in relation to aspirations for knowledge and control. In this way, the photomosaic epistemics of seaweed monitoring and modeling continues in the long genealogy of mosaic strategies for wartime imaging, surveillance, and reconnaissance (Saint-Amour 2011; Parks 2005). 


\section{Acknowledgments}

Thank you to Christina Vagt and Stefan Helmreich for helpful feedback on several drafts of this article. The author would also like to thank Helen Rozwadowski for her reference to John Murray's quote about the mosaic epistemics of oceanography and Alyson Santoro for her invitation to join a scientific research cruise on the R/V Sally Ride in December 2019, which influenced the development of mosaic theory in this article.

\section{Transparency Statement}

The author is a member of the Editorial Advisory Board for Media+Environment. 


\section{REFERENCES}

Arendt, Hannah. (1958) 1998. The Human Condition. Chicago: University of Chicago Press.

Atlantic. 2019. “Great Atlantic Sargassum Belt Is Here to Stay,” July 2019.

https://www.theatlantic.com/science/archive/2019/07/great-atlantic-sargassum-belt-here-stay/ 593290/.

Barad, Karen. 2014. "Invertebrate Visions: Diffractions of the Brittlestar." In The Multispecies Salon, edited by Eben Kirksey, 221-41. Durham: Duke University Press. https://doi.org/10.1215/ 9780822376989-015.

Bell, et al. 2019. “Three Decades of Variability in California’s Giant Kelp Forests from the Landsat Satellites.” Remote Sensing of Environment 238.

Carson, Rachel. 1951. “The Sea - Unforgotten World.” The New Yorker, June 2, 1951.

Cartwright, Nancy. 1999. The Dappled World: A Study of the Boundaries in Science.

Chow, Rey. 2006. Age of the World Target: Self-Referentiality in War, Theory, and Comparative Work. Durham: Duke University Press. https://doi.org/10.2307/j.ctv1198xbg.

Coleridge, Samuel Taylor. (1798) 2013. “The Rime of the Ancient Mariner.” In Lyrical Ballads, edited by Ernest Hartley Coleridge, 190-95. Abingdon, Oxon: Routledge. https://doi.org/ 10.1093/oseo/instance.00088564.

Figueroa, Beatriz Llenin. 2012. "Imagined Islands: A Caribbean Tidalectics.” Dissertation, Duke University Program in Literature.

Gabrys, Jennifer. 2016. Program Earth: Environmental Sensing Technology and the Making of a Computational Planet. Minneapolis: University of Minnesota Press. https://doi.org/10.5749/ minnesota/9780816693122.001.0001.

Guardian. 2018. "Caribbean Swamped by Seaweed That Smells like Rotten Eggs," November 16, 2018. https://www.theguardian.com/environment/2018/nov/16/caribbean-swamped-by-seaweedthat-smells-like-rotten-eggs,.

Haraway, Donna. 1988. "Situated Knowledges: The Science Question in Feminism and the Privilege of the Partial Perspective.” Feminist Studies 14 (3): 575-99.

- - 2007. When Species Meet. Minneapolis: Minnesota Press.

Helmreich, Stefan. 2009. Alien Ocean: Anthropological Voyages in Microbial Seas. Los Angeles: University of California Press. https://doi.org/10.1525/9780520942608.

$\mathrm{Hu}$, Chuanmin. 2019. "A Novel Ocean Color Index to Detect Floating Algae in the Global Oceans." Remote Sensing of Environment 113 (10): 2118-29. https://doi.org/10.1016/j.rse.2009.05.012.

Jue, Melody. 2020. “Oceanography as a Patiently Put Together Mosaic.” May 14, 2020. https:/ppeh.sas.upenn.edu/field-notes/blue-notes-part-2-oceanography-patiently-put-togethermosaic.

Kaplan, Caren. 2018. Aerial Aftermatbs: Wartime from Above. Durham: Duke University Press.

“Mosaic.” n.d. In Oxford English Dictionary. Accessed July 10, 2020.

"Mosaicked.” n.d. In Oxford English Dictionary. Quoted in Forest Resources Arizona 40, Dec. 1990. Accessed July 10, 2020.

Mouritsen, Ole G. 2013. Seaweeds: Edible, Available, Sustainable. Chicago: University of Chicago Press. https://doi.org/10.7208/chicago/9780226044538.001.0001.

Murray, John. 1912. The Depths of the Ocean; a General Account of the Modern Science of Oceanography Based Largely on the Scientific Researches of the Norwegian Steamer Michael Sars in the North Atlantic. London: Macmillan. https://doi.org/10.5962/bhl.title.62194. 
Parks, Lisa. 2005. Cultures in Orbit: Satellites and the Televisual. Durham: Duke University Press. https://doi.org/10.1515/9780822386742.

Perloff, Marjorie. (1995) 2018. "What Has Occurred Only Once: Barthes's Winter Garden/ Boltanski's Archives of the Dead.” In The Photography Reader: History and Theory, edited by Liz Wells. New York: Routledge.

Saint-Amour, Paul. 2011. "Applied Modernism: Military and Civilian Uses of the Aerial Photomosaic.” Theory, Culture छ'Society 28 (7/8): 241-69.

South Florida Caribbean News. 2019. "Sargassum Seaweed Clean-up Costs Caribbean US\$120 Million,” 2019. https://sflcn.com/sargassum-seaweed-clean-up-costs-caribbean-120-million/.. Steyerl, Hito. 2013. HOW NOT TO BE SEEN: A Fucking Didactic Educational .Mov File.

Talbot, William Henry Fox. 1844. The Pencil of Nature. London: Longman, Brown, Green, \& Longmans.

Thompson, Krista A. 2006. An Eye for the Tropics: Tourism, Photography, and Framing the Caribbean Picturesque. Durham: Duke University Press. https://doi.org/10.1215/9780822388562.

Virilio, Paul. (1977) 2006. Speed and Politics. Los Angeles: Semiotext(e).

Wang, Mengqiu, Chuanmin Hu, Brian B. Barnes, Gary Mitchum, Brian Lapointe, and Joseph P. Montoya. 2019. “The Great Atlantic Sargassum Belt.” Science 365 (6448): 83-87. https://doi.org/ 10.1126/science.aaw7912. 